\title{
Escola: lugar de estudar e de comer
}

\author{
School: a place for studying and eating
}

\author{
Maria do Carmo Soares de Freitas ${ }^{1}$ \\ Maria Cecília de Souza Minayo ${ }^{2}$ \\ Lilian Barbosa Ramos ${ }^{1}$ \\ Gardênia Vieira Fontes ${ }^{1}$ \\ Ligia Amparo Santos ${ }^{1}$ \\ Elizeu Clementino de Souza ${ }^{3}$ \\ Anderson Carvalho dos Santos ${ }^{3}$ \\ Sara Emanuela Mota ${ }^{3}$ \\ Janaina Braga de Paiva ${ }^{3}$ \\ Tânia Mara Bernardelli ${ }^{3}$ \\ Franklin Demétrio ${ }^{4}$ \\ Isadora Menezes $^{3}$
}

${ }^{1}$ Departamento de Nutrição, Escola de Nutrição, Universidade Federal da Bahia. Rua Araújo Pinho 32, Canela. 40110-150 Salvador BA.

carmofreitas@uol.com.br ${ }^{2}$ Claves, Escola Nacional de Saúde Pública, Fundação Oswaldo Cruz. ${ }^{3}$ Centro Colaborador em Alimentação e Nutrição do Escolar (Cecane/UFBA). ${ }^{4}$ Centro de Ciência da Saúde, Universidade Federal do Recôncavo da Bahia.
Abstract This study seeks to discuss the significance of school nutrition expressed by students in public schools from the state of Bahia, Brazil. The objective is to understand the symbolic aspects associated with school nutrition. The results of a survey into the significance of nutrition offered by the Brazilian School Nutrition Program (PNAE) expressed by students from six public schools in municipalities in the state of Bahia, Brazil, are presented. A qualitative approach to understand nutrition at school and notions about healthy food by analyzing oral and written narratives of adolescents is used. The reports point to opposing stances between food in the home and food outside the home. What is customary can appear strange depending on the time and place. In this sense, they do not make an association between healthy food and PNAE. The food culture requires students to eat food on two occasions: breakfast and lunch (or dinner). These are aspects that are distinct, however they must be combined in school, because for these social actors, studying and eating are necessities that complement each other.

Key words The significance of school nutrition, Analysis of narratives, healthy food
Resumo Este estudo tem por objetivo discutir significados sobre alimentação escolar atribuídos por estudantes em escolas públicas na Bahia. Trata-se de compreender aspectos simbólicos associados à alimentação escolar na complexidade do mundo cotidiano da escola. Utiliza-se uma abordagem qualitativa para a compreensão do comer na escola e das noções sobre alimentação saudável, a partir das narrativas orais e escritas desses adolescentes. Os relatos enunciam oposições entre alimentação estranha e familiar e vice-versa. O que é familiar torna-se estranho a depender do tempo/ lugar. Citam diversos exemplos de alimentos que são da tradição, mas que se tornam estranhos ou não habituais ao horário. A cultura alimentar dos estudantes requer a obtenção de alimentos em dois momentos: merenda e almoço (ou jantar). Entidades estas que são distintas, não se mesclam e devem estar presentes na escola, pois para estes atores sociais, estudar e comer são necessidades que se complementam.

Palavras-chave Significados da alimentação escolar, Análise de narrativas, Alimentação saudável 


\section{Introdução}

Este estudo apresenta resultados de uma pesquisa sobre os significados da alimentação escolar (especificamente, refeições oferecidas pelo Programa Nacional de Alimentação Escolar - PNAE) atribuídos por estudantes. O referido programa criado na década de 1950 para atender prioritariamente escolas da rede pública, constitui-se basicamente, na oferta de refeições para o estudante do ensino básico, fornecendo um mínimo de $20 \%$ das suas necessidades nutricionais e contribuindo para o crescimento e desenvolvimento biopsicossocial, a aprendizagem e o rendimento escolar ${ }^{1,2}$

De maneira geral, o PNAE depende das condições administrativas municipais para recepcionar e desenvolver o programa, bem como do modo como os gestores o concebem e entendem o repasse de recursos do governo federal calculado pelo censo escolar. Sobretudo, o PNAE necessita do acompanhamento do Conselho de Alimentação Escolar - CAE, local. Apesar do baixíssimo custo da refeição por estudante (conforme Resolução no 67 do FNDE em 28/12/2009) ${ }^{1}$, há lugares que a alimentação escolar se institui como o melhor momento das crianças na escola, com preparações variadas e comensalidade.

O PNAE atende, nacionalmente, a aproximadamente 45 milhões de crianças e adolescentes ${ }^{2}$. Entretanto, mesmo com sua magnitude e importância social, é preciso conhecer como seus usuários o significam e tentar torná-lo positivo em áreas onde se encontra precário.

Vale lembrar que o PNAE é uma política pública que discursa sobre a complementação da alimentação diária para evitar sensações de fome no momento do ensino/aprendizagem, instituindo um vínculo entre alimentação e escola. Para o estudante que padece de desnutrição, a alimentação do PNAE é fundamental, pois, ao reduzir a privação vivida, a escola inscreve, nesses jovens, um valor social articulado ao comer ${ }^{3}$.

Em meio a tantos objetos observados no cotidiano alimentar das escolas sublinha-se a redução da prevalência da desnutrição, em termos gerais, no $\mathrm{Brasil}^{4}$ e aumento de frequência de sobrepeso e obesidade ${ }^{4,5}$. Um problema de saúde decorrente de hábitos não saudáveis. Desses pressupostos, elege-se neste estudo a compreensão e a interpretação dos significados da alimentação escolar, por estudantes de escolas públicas na periferia da cidade do Salvador e de municípios próximos ao grande centro soteropolitano, onde os efeitos da realidade social, de exclusão e vio- lência se expressam num cotidiano de poucas expectativas de melhoria de vida ${ }^{6}$.

Opta-se em focalizar o cotidiano escolar por entender a importância das interações sociais em cada contexto específico, com seus símbolos e representações da alimentação. A identificação dos significados da alimentação escolar pelo estudante revela sua condição sociocultural e econômica ademais de seus valores culturais sobre o comer-na-escola. Em função da complexidade deste objeto de estudo, busca-se aproximação com disciplinas das ciências humanas para dar suporte a análise das narrativas ${ }^{7-12}$.

\section{Metodologia}

A pesquisa foi realizada durante o período letivo de agosto de 2007 a junho de 2008, em dois grupos de estudantes de escolas públicas: os que recebem o PNAE, e os que já receberam e continuaram na mesma escola, em séries mais avançadas. As escolas escolhidas por pesquisadores do Centro Colaborador em Alimentação e Nutrição do Escolar da Universidade Federal da Bahia (CECANE/UFBA), pela facilidade de acesso e pelo interesse dos supervisores e diretores das escolas em avaliar a aceitação do PNAE por seus estudantes. As escolas estão situadas no centro urbano, subúrbio ferroviário de Salvador, sede do município de Lauro de Freitas e comunidade de Santana no Distrito de Ilha de Maré.

Participaram do estudo 160 escolares adolescentes de 12 a 18 anos, todos das camadas populares. São estes: 1) estudantes das quartas e quintas séries do curso fundamental (já possuem noções de ciências naturais e saúde oferecidas pelos currículos escolares); 2) estudantes da primeira série do ensino médio e recém-egressos do PNAE. Os supervisores pedagógicos assinaram os termos de consentimento livre e esclarecido para a realização da coleta de dados junto aos estudantes.

Solicitou-se redações sobre o tema alimentação na escola e depois realizou-se entrevistas atendendo aos princípios da abordagem qualitativa que privilegia a compreensão dos enunciados dos sujeitos. Estes manifestaram opiniões, sentimentos e experiências sobre o tema investigado ${ }^{7}$. Quanto à metodologia, recorremos aos estudos de Minayo $^{7}$ e Goldemberg ${ }^{8}$ que deram pistas importantes para a realização do trabalho de campo e análises. Outras referências citadas mais adiante atendem especificidades da análise de narrativas. A pesquisa teve as seguintes fases: 
1) Contextualização da organização de cada escola e a estrutura que oferecem para o acesso à alimentação pelo PNAE; a observação registrou práticas alimentares;

2) Contato com escolares que voluntariamente colaboraram com as redações e a realização das entrevistas. Para a obtenção das informações significativas sobre a alimentação na escola, adotase a "técnica de redação" que teve a aquiescência do corpo docente em cada unidade. Sobre isso, autores como, Elizeu Souza ${ }^{9}$ e Paul Ricoeur ${ }^{10}$ consideram a narrativa (escrita e oral) como a possibilidade do sujeito lembrar, eleger e mostrar representações sobre sua identidade, suas práticas, situações que marcam escolhas e aprendizagens. Em cada sala de aula explicou-se aos estudantes o objetivo do trabalho. Depois, fizeram as redações sobre a alimentação na escola. Colaboraram com este trabalho, 120 estudantes das $4^{\mathrm{a}}$ e $5^{\mathrm{a}}$ séries e 40 do curso médio. Ambos os grupos narraram breves parágrafos de suas experiências sobre a alimentação na escola e expressaram seus desejos; o que falta no PNAE; o que gostam de comer ou não; a concepção de fome; alimentos que quiseram destacar ao lembrar a infância, a casa e a rua. Os autores das narrativas escritas foram solicitados a colocar nomes fictícios ou apenas suas iniciais para identificar seus textos.

3) Realizadas entrevistas narrativas conforme a referência de Jovchelovitch e Bauer ${ }^{11}$. A seleção dos entrevistados (total de 30, sendo cinco em cada escola), privilegiou os que apresentaram mais informações nas redações. As entrevistas tiveram a duração de aproximadamente quarenta minutos e seguiram um roteiro de questões sobre a experiência da alimentação oferecida pela escola, hábitos, preferências, motivos de rejeição ou aceitação dos alimentos, opiniões sobre o comer na vida cotidiana.

4) As informações obtidas foram analisadas com a minuciosa leitura, agrupando categorias e selecionando os termos significantes semelhantes e opostos ${ }^{9,12,13}$. Valorizam-se as experiências pessoais no cotidiano da escola, sobretudo os significados da alimentação oferecida pelo PNAE.

\section{A análise das narrativas dos escolares}

Das narrativas (redações e entrevistas transcritas) emergiram indícios relembrados da infância, sensações do comer, valores simbólicos, noções de necessidade que ora se confundiam com fragmentos de discursos técnicos científicos, obtidos em conteúdos disciplinares da escola, ora eram apreensões das tradições familiares.
Os textos redigidos por escolares, alguns com duas frases, outros com quatro e cinco parágrafos, formaram um volume suficiente para dar aos pesquisadores a certeza de que a lógica interna desses sujeitos estava definida e de que seria possível encontrar categorias de análise $\mathrm{e}^{7,12}$. Ao imergir na interpretação dos conteúdos agregouse informações da observação dos pesquisadores sobre as práticas alimentares no recreio, conversas entre os escolares, brincadeiras e silêncios durante as refeições.

No processo de análise elegeu-se dois eixos centrais para dar conta das contradições internas sobre a alimentação: familiaridade e estranhamento. Um diz respeito à aceitação, outro, expressa recusa às preparações e a outros alimentos oferecidos. A partir desses eixos, surgiram as categorias:1) "o lugar do alimento"; 2) “o não-lugar" ou "fora-de-lugar" do alimento; 3 ) a noção de saudável como bem.

\section{Resultados e discussão}

Do ponto de vista dos escolares, existe uma força na dualidade entre bom ou ruim de comer. Nas narrativas, surge a intertextualidade que se associa a lugares, aparências, gosto, sociabilidade, familiaridade e estranhamento. Colocam-se em jogo termos contraditórios, em que o familiar se torna estranho e vice-versa. É considerado estranho a associação banana e biscoito; laranja e pão; mingau de tapioca com gosto de remédio; feijão ou sopa no meio da manhã ou no meio da tarde, ou no lugar do recreio. São alimentos familiarizados, mas ao mesmo tempo estranhados, pois, encontram-se fora-do-lugar da tradição, do hábito. Para a cultura da região, sopa é jantar, e se oferecida fora desse lugar torna-se comida de doente ou de idoso. Para os escolares tomar sopa no recreio está errado ou não é saudável. Referem-se a merenda e a comida como entidades distintas sendo a primeira prazerosa e a segunda uma necessidade. Gostariam de merendar qualquer coisa ou uma besteira, diferente do que poderiam comer no almoço ou no jantar, na escola. O termo besteira nas escolas urbanas (a exceção de Ilha de Maré) está no mesmo campo semântico que merenda e brincadeira.

Embora nos últimos anos algumas mudanças efetuadas na normatividade do PNAE tenham contribuído para avanços na concepção do programa como política educacional também voltada à alimentação saudável, a observação do cotidiano das escolas visitadas mostra algumas difi- 
culdades neste processo. De maneira geral, o PNAE oferece apenas uma refeição. Os jovens não se sentem alimentados como gostariam, pois para eles vários tipos de refeições encontram-se fora-de-lugar. E ninguém explica porque nos dão sopinha na merenda (ME). A sopa é uma refeição comum neste programa, mas sugerida pelos escolares para ser oferecida no jantar, como o habitual em suas unidades domésticas.

Em geral, as relações domésticas - aquelas que os antropólogos denominam relações primárias - são as que produzem hábitos que atendem às necessidades básicas ${ }^{13}$. $\mathrm{Na}$ familiaridade há referências, identidades, aceitação e valores pertencentes à percepção de todas as coisas da naturalidade do cotidiano. É familiar o tempo e o lugar de comer determinados alimentos, preparações, como um hábito que se adquire em cada contexto situacional.

A implementação do PNAE promove uma resistência típica em crianças e adolescentes nestes ambientes estudados. Observa-se que no momento da merenda, algumas vezes, escolares jogam alimentos uns nos outros, como a guerra de laranjas, outros gritam que não querem comer alguns alimentos (em geral sopas e mingaus de milho e aipim). A recusa é motivada porque, no imaginário dos escolares, estas preparações são representacionais da condição senil e infantil. Significa que não devem ser oferecidos na escola, mas em casa, ou devem estar em outro lugar (no jantar). Sobre o mingau costumam dizer: Não sei por que dão papinha de neném pra gente (LF).

Em outras palavras, as práticas alimentares na escola são como unidades conservadas, inalteradas e sem avaliação. Na interpretação de alguns jovens: É sempre a mesma sopa (AS). Sopa de manhã é horrível. A gente come porque não tem outra coisa (BN).

Não se trata de analisar o familiar e o estranho como sistemas incompatíveis, um em relação ao outro, mas relacioná-los como duas maneiras de decifrar a lógica do programa. Nesse aspecto, diversos termos analíticos se conectam a estas estruturas gerando uma relação estratégica e polissêmica sobre a alimentação na escola: Só como aqui porque não tem jeito (MS). Ou o contrário: Adoro tudo. O feijão é melhor (SA); E ainda: Todo dia é igual: sopa ruim, mingau ruim; Lanche bom é só o de mãe (AM). Tem vezes que eu como e às vezes que não dá para comer, é muito ruim, e vou passando (NA). Esta aluna de onze anos, passa pela merenda, como um rito estratégico de aceitação do alimento, porque o necessita. Aqui, e em outros momentos, há construções de autodesignações sobre necessidade em oposição ao prazer de comer.

Nas narrativas há termos significantes, unidades léxicas como palavras ou sentenças que se articulam entre os textos para dar sentido ${ }^{12,13}$ ao comer na escola. A análise se torna complexa pela pluralidade dos sentidos que circulam entre a aparência da refeição e a experiência do comer de cada estudante.

Entre familiaridade e estranhamento formam-se duas imagens: o lugar e o não lugar, quebrando o sistema binário anterior. Merenda é lugar de lanche leve, frutas ou sucos, momento de recreio. A alimentação pode estar fora-de-lugar quando não se combina com o recreio, ou seja, quando se oferece uma refeição culturalmente concebida como almoço ou jantar. Nesses casos, o alimento perde sentido cultural e por isso os escolares não se sentem alimentados como gostariam. Ainda que gostem de feijão tropeiro, entendem que é errado comer esta refeição no meio da manhã. Para tanto, expressam justificativas. Dizem que os alimentos do programa não são os de sua geração e que o lugar da merenda (ou do recreio) é invadido por comidas. Com isso há uma ruptura do sentido de recreação, pois o recreio é lugar de brincar e nesse sentido se deveria comer besteira. Sobre isto, vale lembrar o clássico estudo coordenado por Woorthman ${ }^{14}$ em 1978, ao analisar o termo besteira como lanche, usado em várias cidades do país (ainda hoje, esta expressão possui semelhante conotação).

O sentido de fome, presente nas narrativas, aparece em ambos os grupos de escolares. Entretanto, o comer na escola fica mais evidente em narrativas dos que estão vivenciando o programa. Eles falam de fome e necessidade: A gente engana a fome com essa merenda para não ter mais vontade de almoçar (NA); Pra mim não adianta: como e fico sentindo falta (AS); Falar dessas coisas (fome) dá vergonha (CM). Essa merenda engana a barriga (PL); é tapeação (NA).

Em diferentes contextos não se observou diferenças culturais acentuadas. Alguma variação aparece no sentido de aceitação ou rejeição de mingaus de milho e mandioca. Estes são mais aceitos na comunidade tradicional de pesca que na região urbana.

Há escolares que consomem quaisquer refeições oferecidas pelo PNAE, outros rejeitam certos cardápios. Alguns, sem dinheiro para comprar produtos dos pequenos comércios de alimentos na vizinhança da escola, sentem-se forçados a consumir o que lhes são oferecidos, mesmo sendo alimentos processados, lácteos com soja, fora de seus 
hábitos. Com isso, há reações: passam mal, vomitam, sentem náuseas, estranham produtos industrializados com sabores de morango. Há situações inversas, e querem repetir a merenda.

A alimentação na escola tem relação com a comida da casa e há sempre um hábito a se adquirir. Hábito enquanto inscrição da cultura e da identidade dos sujeitos, uma condição estruturante $^{3}$. Em geral, o hábito alimentar referente ao almoço desses escolares, no cotidiano doméstico, é predominantemente à base de farinha de mandioca, feijão, carne seca, frango, macarrão. Quase não há verduras. Às vezes, em casa a gente come abóbora, maxixe e quiabo (MJ). Quando não há condições de manter o feijão diário, come-se pirão de farinha com temperos. À noite é quase sempre pão com margarina ou cuscuz de milho, biscoitos, café. Conforme alguns enunciados, a principal alimentação está na escola, porque em casa não há para todos. Mãe pede pra comer tudo que a escola dá (AS).

E ao relembrar da alimentação na escola, os estudantes do ensino médio se curvam em silêncio e escrevem: A hora da merenda era a mais esperada; a melhor parte do colégio. Não me lembro de coisa ruim. Adorava almôndegas de soja, arroz com soja bem temperado (MA). O que era ruim a gente não lembra mais; uns vomitavam a sopa, isso não esqueci (AM). A merenda ajudava todo mundo (PA).

Nas conversas com os escolares do curso fundamental, escola é lugar de comer, encontrar amigos, namorar, estudar português e matemática. Não há dúvidas que entre os sexos ocorrem diferentes valores sobre o comer. O vínculo da alimentação com o feminino ocorre desde cedo. As meninas adquirem um modo de pensar o cuidado alimentar distinto do menino ${ }^{15}$. Mas ambos entendem o comer como necessidade física e satisfação emocional. A distinção de gênero neste estudo está em relação à aparência do alimento. São as adolescentes, em todas as escolas pesquisadas, que mais reclamam da falta de higiene dos alimentos e expressam com maior ênfase sobre a importância de comer o que a escola pode oferecer. São elas que falam da necessidade de uma alimentação saudável. Cuidado e gênero ficam em evidência. Para meninos e rapazes, merenda no lugar do horário do recreio deveria ser apenas lanches. Tanto as adolescentes quanto eles entendem o recreio como lugar de recriação, com brincadeiras de correr e gritar, dar risada, um rito diferenciador do espaço das aulas.

Ao comparar as redações dos dois grupos, identificamos semelhanças, a exemplo da rejeição que sentem por sopa quando servida no meio da manhã, e da falta de comensalidade motivada por precárias condições físicas na escola. Ninguém conseguia se sentar para comer e conversar (uma estudante do ensino médio ao relembrar o PNAE).

Tempo e espaço da alimentação escolar são expressos através de frases bastante significativas: Recreio não é lugar de comida; comida é meio dia, sopa é jantar; recreio é para brincar, e qualquer alimento oferecido no momento do recreio é besteira. Mais significativas são as tipificações sobre tempos e lugares de comer: Lanche e comida é em casa; merenda é na escola; besteira é na rua; alimentação saudável (referindo-se às teorias sobre nutrição) só nos cadernos.

Por saudável, entendemos um tipo de alimentação que garante nutrientes necessários aos processos fisiológicos para o desenvolvimento físico e mental do indivíduo, em correspondência com os hábitos alimentares regionais ${ }^{16}$. Na matéria que trata das ciências naturais nas escolas públicas estudadas, constatou-se que desde a quarta série há conceitos explicativos sobre alimentos, principais nutrientes e organismo humano. Com isto, os professores tentam mostrar as fontes de minerais e vitaminas dos alimentos que estão na natureza. É transmitida para eles a noção de saudável como um bem para o corpo. Entretanto, em geral, os conteúdos estão dissociados do cotidiano sociocultural dos estudantes.

Escolares do curso fundamental atribuem significados ao saudável, referindo-se ao bem-estar do corpo. A alimentação saudável é concebida como pureza do corpo, uma espécie de renovação dietética. Reconhecem que: Não se deve comer fritura por causa do colesterol, pode fazer mal ao coração (VN). Colesterol suja o sangue (SM). O certo é comer feijão e verduras, o sangue fica bom (ES). Entendem que podem comer besteiras como batatas fritas e doces, depois fazer dieta para limpar o sangue. Uma estudante diz que saudável é comer o que gosta e não fazer exagero (BN).

As noções sobre alimentação saudável são retiradas de proposições generalizadas da abordagem biomédica, que autorizam essa representação para qualquer grupo humano, independente de onde viva ${ }^{16}$. Na sala de aula, em geral, não se faz relação entre alimentos, saúde, indivíduos e sociedade, com isso, há um vazio de entendimento entre noções do "saudável instituído" e os hábitos alimentares.

Com as insatisfações dos escolares sobre as refeições do PNAE, surgem ofertas alternativas dentro e fora do estabelecimento: lanches de frituras (pastéis e coxinhas de frango); e muitas 
vezes há cantinas no interior da escola para a venda de balas, refrigerantes, pipocas etc. E mesmo reconhecendo noções sobre alimentação saudável, os escolares nem sempre fazem relação entre saúde e PNAE. Consequentemente, merenda é brincadeira de recreio e não é nada sério!

Os escolares preferem salsicha no pão e batatinha frita; reconhecem que trocariam um prato de almoço por um cachorro-quente ou um sanduíche misto. Na comunidade tradicional de pesca já existem novos valores do comer produzindo principalmente nos jovens, atração e desejo por lanches midiáticos: hambúrgueres e refrigerantes.

Entretanto, ainda que não tenham este tipo de lanche na escola entendem que não pode haver escola sem merenda. Para eles escola é lugar de estudar e de comer. E o lugar de comer é no tempo do recreio, do almoço ou do jantar. Ser saudável é fazer parte desse tempo, para outros é sentirem-se livres para comer o que quiserem. Ainda há os que entendam a racionalidade do bem para o corpo como uma necessidade conforme aprendem nas aulas de ciências na quarta série do curso fundamental.

\section{Conclusão}

A ênfase colocada na percepção dos escolares sobre o comer na escola confirma que estes possuem uma cultura alimentar e são também influenciados por novidades do mercado consumidor e pela propaganda. Essa dinâmica ocorre independentemente do apelo da escola de se ter uma alimentação saudável. Também os escolares manifestam a necessidade de alimentarem-se na escola.

As categorias alimento-familiar e estranho influenciam a construção de outras percepções como: alimento do lugar e alimento fora-de-lugar (esta estrutura nega o recreio como lugar de comida). Estranham alimentos fora-do-lugar do hábito; ou mesmo familiar, o alimento pode se tornar estranho se for oferecido num tempo distinto do habitual. Este é um dos motivos da rejeição de algumas refeições do PNAE.

Conclui-se que os escolares desejam obter merenda e comida. Estas são entidades concretas e distintas em tempo e espacialidade, como ocorre na tradição alimentar da sociedade brasileira. No entanto, no campo simbólico, para estes es- colares entrevistados, são expressões que também representam a qualidade da alimentação escolar. Para eles, a merenda oficial, ao tomar o lugar do recreio, deveria oferecer apenas coisas prazerosas e não comida sem gosto (AM) ou comida séria (ME). Comida séria é almoço ou jantar e nunca uma merenda. Entende-se que o PNAE necessita enfatizar ações educativas para obter outras significações de seus consumidores. Para eles, há pouca variedade de cardápios no PNAE e o que mais desejam são os alimentos midiáticos ou de rua como batata-frita, refrigerante, biscoitos recheados, pipoca doce etc. Estes alimentos representam para os atores sociais o sentido de estarem-no-mundo-moderno, globalizado, midiático. São os lanches do deleite. Sobre isto, somente um projeto de educação poderia apreender novos sentidos da cultura local ${ }^{3}$ gerando alternativas saudáveis aos alimentos midiáticos nocivos à saúde.

A alimentação escolar oferecida pelo PNAE pode ser repensada para atender às solicitações significativas da cultura dos escolares em seus contextos sociais. Pois, além do fornecimento das refeições, o programa, que tem nas suas diretrizes o fortalecimento das ações educativas, ao se operacionalizar na grande rede escolar, enfrenta dificuldades para instituir na comunidade escolar de maneira transversal e interdisciplinar, uma preocupação com alimentação e saúde e a assunção dos atos de nutrição e alimentação como rituais do cotidiano. Todas as informações aqui analisadas permitem refletir ações do PNAE considerando a carência alimentar dos estudantes, seus desejos e hábitos. E, sendo o comer um ato cultural tão profundo e carregado de significa$\operatorname{dos}^{17}$, é importante que a lógica pedagógica da alimentação da escola vá ao encontro dos significados que os próprios estudantes aportam sobre a escola e o comer. Embora este aspecto já tenha sido acolhido pela dimensão normativa da alimentação escolar, é necessário ser pensado e assumido no âmbito mesmo da escola - onde as especificidades locais, regionais e globais ganham expressão - e traduzido em ações criativas. A disposição para uma relação dialógica entre a escola e a sua comunidade assistida poderá sinalizar na direção de uma compreensão e enfrentamento dos aspectos envolvidos com o comer saudável na escola. 


\section{Colaboradores}

MCS Freitas, MCS Minayo, LB Ramos, GV Fontes, LA Santos, EC Souza, AC Santos, SE Mota, JB Paiva, TM Bernardelli, F Demétrio e I Menezes participaram igualmente de todas as etapas de elaboração do artigo.

\section{Referências}

1. Brasil. Resolução CD/FNDE n ${ }^{\circ} 38$ de 16 de julho de 2009. Dispõe sobre o atendimento da alimentação escolar aos alunos da educação básica no Programa Nacional de Alimentação Escolar - PNAE. Diário Oficial da União 2009; 16 jul.

2. Brasil. Alimentação Escolar. [acessado 2011 set 23]. Disponível em: http://www.fnde.gov.br/index.php/ programas-alimentacao-escolar.

3. Bezerra JAB. Alimentação e escola: significados e implicações curriculares da merenda escolar. Revista Brasileira de Educação 2009; 14(Supl. 40):103-115.

4. Batista Filho M, Rissin A. A transição nutricional no Brasil: tendências regionais e temporais. Cad Saude Publica 2003; 19(Supl. 1):s181-s191.

5. Guedes DP, Miranda Neto JT, Almeida MJ, Silva AJRM. Impacto de fatores sociodemográficos e comportamentais na prevalência de sobrepeso e obesidade de escolares. Rev. bras. cineantropom. desempenho hum 2010; 12(Supl. 4):221-231.

6. Freitas MCS. Agonia da fome. Salvador: Edufba, Fiocruz; 2003.

7. Minayo MCS. Desafio do conhecimento: pesquisa qualitativa em saúde. 3a Edição. São Paulo, Rio de Janeiro: Hucitec, Abrasco; 1994.

8. Goldenberg M. A arte de pesquisar: como fazer pesquisa qualitativa em Ciências Sociais. Rio de Janeiro: Record; 1997.

9. Souza EC. História de vida e formação de professores: um olhar sobre a singularidade das narrativas (auto) biográficas. In: Macedo RS, organizador. Currículo e Docência: tensões contemporâneas interfaces pós-formais. Salvador: UNEB; 2003. p. 35-56.

10. Ricoeur P. Tempo e narrativa. V. 3. Campinas: Papirus; 1997.

11. Jovchelovitch S, Bauer M. Entrevista Narrativa. In: Bauer MW, Gaskell G, organizadores. Pesquisa Qualitativa com Texto, Imagem e Som: Um manual prático. 6a Edição. Petrópolis: Vozes; 2007.

12. Barthes R. Elementos de semiologia. 10a Edição. São Paulo: Cultrix; 1997.

13. Eco U. A estrutura ausente. 7a Edição. São Paulo: Perspectiva; 1991.

14. Woortman K. Hábitos e tabus alimentares em populações de baixa renda. [periódico na Internet]. 1978. [acessado 2012 jan 12]. Disponível em: http:/ /www.scribd.com/doc/ 51552681/Woortmann-K1978

15. Counihan CM. The antropology of food and body: gender, meaning and power. New York: Routledge; 1999.

16. Brasil. Ministério da Saúde (MS). Guia alimentar para a população brasileira. Brasília: MS [periódico na Internet]. 2005. [acessado $2011 \mathrm{dez} 11$ ]. Disponível em: http://dtr2001.saude.gov.br/editora/produtos/livros/ pdf/05_1109_M.pdf

17. Arnaiz MG. No comerás: narrativas sobre comida, cuerpo y género en el nuevo milenio. Barcelona: Içaria, Observatorio de La Alimentación; 2007.

Artigo apresentado em 03/01/2013

Aprovado em 05/01/2013

Versão final apresentada em 08/01/2013 
